\title{
Analisis Kesiapan Rumah Sakit Dharma Kerti Tabanan Menerapkan Rekam Medis Elektronik
}

\author{
Made Karma Maha Wirajaya ${ }^{1}$, Ni Made Umi Kartika Dewi ${ }^{2}$ \\ Program Studi Manajemen Informasi Kesehatan, Universitas Bali Internasional ${ }^{1,2}$ \\ mdkarma.wirajaya@gmail.com ${ }^{1}$
}

\begin{abstract}
Diajukan 30 Desember 2019 Diperbaiki 15 Februari 2020 Diterima 18 Februari 2020 ABSTRAK

Latar Belakang: Rumah Sakit Dharma Kerti Tabanan adalah rumah sakit swasta yang berlokasi di Kabupaten Tabanan. Adanya keterbatasan ruang penyimpanan rekam medis dan juga upaya rumah sakit untuk meningkatkan kualitas pelayanan maka manajemen rumah sakit memilih untuk menerapkan Rekam Medis Elektronik.

Tujuan: Menganalisis kesiapan Rumah Sakit Dharma Kerti Tabanan dalam menerapkan RME.

Metode: Penelitian ini adalah penelitian cross sectional dengan pendekatan kuantitatif dan kualitatif. Sampel yang digunakan yaitu sebanyak 82 orang pegawai dan dilakukan wawancara terhadap 7 orang pegawai. Analisis kesiapan dilakukan dengan metode DOQ-IT (Doctor's Office Quality-Information Technology). Variabel yang diteliti dengan kuantitatif dan kualitatif adalah

kepemimpinan, sumber daya manusia dan infrastruktur.

Hasil: Rumah Sakit Dharma Kerti Tabanan telah cukup siap dalam menerapkan RME. Secara kuantitatif, dilihat dari budaya organisasi, rumah sakit telah cukup siap yakni $68.57 \%$. Dilihat dari tata kelola yakni $71.43 \%$ dan dilihat dari sumber daya manusia rumah sakit yakni $57.14 \%$. Selain itu dilihat dari infrastruktur yakni $58.57 \%$. Secara kualitatif, masih terdapat beberapa kekurangan yakni belum ada pelatihan, belum memliki SOP, pemimpin belum membentuk tim khusus dan belum memiliki IT yang memadai.

Kesimpulan: Rumah Sakit Dharma Kerti Tabanan telah cukup siap menerapkan RME dan masih terdapat beberapa kelemahan yang perlu diperbaiki.
\end{abstract} kesiapan budaya organisasi, tata kelola dan

Kata Kunci: analisis; kesiapan; rumah sakit; rekam medis elektronik

\section{ABSTRACT}

Background: Dharma Kerti Tabanan Hospital is a private hospitals located in Tabanan Regency. Due to limited storage space for medical records and hospital efforts to improve service quality, hospital management chose to implement Electronic Medical Records.

Objective: The study aim to analyze the readiness of Dharma Kerti Tabanan Hospital in implementing RME Methods: This research is a cross sectional study with quantitative and qualitative approaches. The sample used 82 employees and interviews with 7 employees. The readiness analysis use the DOQ-IT (Doctor's Office Quality-Information Technology). The variables studied are organizational culture readiness, governance and

\section{leadership, human resources and infrastructure}

Results: The Dharma Kerti Tabanan Hospital is quite ready in implementing $R M E$. Quantitatively, seen from the organizational culture, hospitals are quite ready at $68.57 \%$. Judging from the governance of $71.43 \%$ and seen from the hospital's human resources that is $57.14 \%$. Also seen from the infrastructure is $58.57 \%$. Qualitatively, there some weaknesses such as there is no training, there is no SOP, leaders have not formed a special team and do not have adequate IT

Conclusion: Dharma Kerti Tabanan Hospital is quite ready in implementing RME and there are still some weaknesses that need to be corrected

Keywords: analysis; readiness; hospital; electronic medical records 


\section{PENDAHULUAN}

Rumah sakit merupakan sebuah organisasi yang bersifat padat karya, modal serta teknologi. Pertumbuhan rumah sakit saat ini sangat meningkat pesat sehingga terjadi persaingan di dalam dunia kesehatan (Andini, 2006).

Rumah sakit wajib meningkatkan kualitas mutu pelayanan kesehatan dengan cara memanfaatkan perkembangan teknologi saat ini agar dapat bersaing dengan baik. Salah satu perkembangan teknologi tersebut adalah Rekam Medis Elektronik (RME). Penggunaan RME merupakan pengaplikasian sebuah teknologi informasi yang digunakan dalam pengumpulan, penyimpanan data, pengolahan data serta pengaksesan data yang tersimpan pada rekam medis pasien di sebuah rumah sakit dalam suatu sistem manajemen basis data yang menghimpun berbagai macam sumber data medis (Handiwidjojo, 2009).

Perkembangan RME ini tidak hanya terjadi pada negara maju tetapi juga terjadi di negara berkembang seperti di indonesia (Kalogriopoulos, 2014). Perkembangan RME di Indonesia belum diatur secara khusus tetapi dengan adanya dukungan dari Permenkes No. 269 Tahun 2008 tentang keabsahan RME sebagai bukti hukum memberikan harapan cerah bagi perkembangan RME di Indonesia (Sudjana, 2017). Penerapan RME di rumah sakit dipercaya dapat meningkatkan kualitas keseluruhan perawatan (Tavakoli et al, 2011) dan beberapa penelitian juga menunjukkan peran RME terhadap patient safety (Venkatraman, 2008).

RME sangat penting bagi manajemen untuk mengelola masalah kesehatan karena menyediakan integritas dan akurasi dan juga dapat menjadi solusi untuk meningkatkan efisiensi biaya, peningkatan akses dan kualitas pelayanan di rumah sakit (Qureshi et al, 2012). Manfaat RME bagi tenaga medis adalah sebagai dasar atau petunjuk untuk merencanakan dan menganalisis sebuah penyakit, merencanakan sebuah pengobatan, perawatan dan tindakan medis yang harus diberikan kepada pasien serta dapat meningkatkan kualitas pelayanan sehingga melindungi tenaga medis untuk mencapai kesehatan masyarakat yang optimal. Namun untuk menerapkan RME dijumpai begitu banyak tantangan yang sedemikian kompleks.

Beberapa diantaranya adalah kurangnya definisi seragam akan konsep pengembangan teknologi informasi, kurangnya penilaian kebutuhan sebelum pelaksanaan, adanya kekhawatiran akan terjadinya pelanggaran privasi dan kasus hukum. Tantangan yang lain adalah kurangnya integrasi dan sharing oleh berbagai level manajemen. Penilaian kesiapan akan membantu identifikasi proses dan skala prioritas. Kurangnya kesiapan organisasi adalah penyumbang utama kegagalan RME di industri kesehatan. Beberapa penelitian pada tahun 1999 telah menunjukkan bahwa salah satu faktor yang menyebabkan $50 \%$ institusi kesehatan gagal mengimplementasikan RME adalah karena kurang siapnya rumah sakit dalam mengimplementasikan RME (SnyderHalpern, 2001).

Penilaian kesiapan juga merupakan cara untuk mengidentifikasi potensi penyebab kegagalan dalam inovasi (Ajami et al, 2011). Rumah Sakit Dharma Kerti Tabanan adalah rumah sakit swasta yang berlokasi di Kabupaten Tabanan. Karena keterbatasan ruang penyimpanan rekam medis dan juga upaya rumah sakit untuk meningkatkan kualitas pelayanan maka manajemen rumah sakit memilih untuk menerapkan RME. Berdasarkan hal tersebut maka peneliti ingin menganalisa kesiapan Rumah Sakit Dharma Kerti Tabanan dengan menggunakan metode DOQ-IT (Doctor's Office Quality-Information Technology).

\section{METODE}

Jenis penelitian ini adalah menggunakan metode penelitian kuantitatif dan kualitatif. Metode penelitian kuantitatif digunakan untuk mengetahui gambaran kesiapan rumah sakit sedangkan metode penelitian kualitatif digunakan untuk menggali hal yang telah siap 
dan belum siap sehingga dapat mendukung hasil penelitian kuantitatif yang didapatkan. Variabel yang diteliti baik kuantitatif maupun kualitatif adalah variabel kesiapan budaya organisasi, kesiapan tata kelola dan kepemimpinan, kesiapan sumber daya manusia dan kesiapan infrastruktur Desain penelitian ini adalah cross sectional.

Penelitian ini dilakukan di Rumah Sakit Dharma Kerti dan waktu pengumpulan data dilakukan pada bulan Juni sampai dengan Juli 2019. Penelitian ini menggunakan sumber data primer dan sekunder. Pada pendekatan kualitatif, data primer dikumpulkan melalui wawancara mendalam menggunakan pedoman wawancara sedangkan pada pendekatan kuantitatif, data primer dikumpulkan melalui kuesioner yang dibagikan oleh peneliti.

Kuesioner merupakan modifikasi dari kuesioner DOQ-IT (Doctor's Office QualityInformation Technology) yang telah valid dan reliabel untuk mengukur kesiapan rumah sakit menerapkan rekam medis elektronik. Populasi penelitian pada pendekatan kuantitatif adalah tenaga kesehatan. Populasi terjangkau penelitian ini adalah tenaga kesehatan di Rumah Sakit Dharma Kerti Tabanan yang berjumlah 82 orang. Pengambilan sampel pada pendekatan kuantitatif menggunakan metode total sampling yaitu seluruh tenaga kesehatan yang masuk dalam kriteria inklusi yaitu :

Informan pada pendekatan kualitatif diambil dengan metode purposive sampling yaitu peneliti memilih responden dengan pertimbangan bahwa responden dapat memberikan informasi yang memadai untuk menjawab pertanyaan terhadap kuesioner peneliti. Informan yang terlibat pada penelitian ini berjumlah 7 informan yang terdiri dari:

1. Direktur Rumah Sakit Dharma Kerti Tabanan

2. Kepala bidang keuangan di Rumah Sakit Dharma Kerti Tabanan

3. Kepala bidang pelayanan medis di Rumah Sakit Dharma Kerti Tabanan

4. Kepala bidang IT di Rumah Sakit Dharma Kerti Tabanan
5. Petugas Rekam Medis di Rumah Sakit dharma Kerti Tabanan

6. Dokter di Rumah Sakit Dharma Kerti Tabanan

7. Perawat di Rumah Sakit Dharma Kerti Tabanan

Metode yang digunakan untuk analisis kesiapan rumah sakit adalah DOQ-IT dengan indikator meliputi kesiapan SDM, kesiapan budaya kerja organisasi, kesiapan tatakelola dan kepemimpinan serta kesiapan infrastruktur. Instrumen yang digunakan dalam penelitian ini adalah kuesioner dan pedoman wawancara serta lembar observasi. Pada pendekatan kualitatif teknik analisa data dilakukan secara simultan melalui proses pengumpulan data.

Hasil wawancara yang sudah direkam di transformasi dalam bentuk tulisan. Bentuk tulisan selanjutnya akan dibuat dalam sebuah transkrip yang akan dibaca oleh peneliti untuk memastikan keakuratannya. Data yang telah terkumpul diberikan kode dengan memberikan angka 1, 2, 3, 4 dan seterusnya. Kode P1 diberikan pada informan 1, P2 pada informan 2 dan seterusnya. Pengkodean ini dilakukan untuk membedakan antara transkrip informan satu dengan informan yang lainnya.

Pada pendekatan kualitatif ini dilakukan uji keabsahan data menggunakan metode triangulasi. Menurut Wiliam Wiersma dalam Sugiyono (2008) triangulasi adalah cara mengevaluasi data dari berbagai sumber menggunakan metode dan waktu yang berbeda. Teknik triangulasi sumber data digunakan pada penelitian ini yang dilakukan melalui pengecekan data yang bersumber dari direktur, perawat, dokter petugas rekam medis dan hasil observasi serta studi literatur yang berhubungan dengan persiapan penerapan RME.

Data yang diperoleh dari sumber itu dideskripsikan selanjutnya dikategorisasikan untuk mengelompokkan mana ide yang sama, spesifik, berbeda, valid dan reliabel. Analisis statistik yang digunakan pada pendekatan 
kuantitatif adalah statistik deskriptif. Analisis ini bertujuan untuk menggambarkan kesiapan SDM di Rumah Sakit Dharma Kerti dalam menerapkan RME. Adapun kategori untuk menilai kesiapan rumah sakit dalam menerapkan RME adalah sebagai berikut.

Tabel 1. Interpretasi Penilaian Kesiapan Implementasi RME

\begin{tabular}{|c|c|c|}
\hline $\begin{array}{c}\text { Kisaran } \\
\text { Skor }\end{array}$ & Interprestasi & Keterangan \\
\hline $\begin{array}{c}\mathrm{I} \\
98-145\end{array}$ & $\begin{array}{l}\text { Skor ini menunjukkan } \\
\text { bahwa sumber daya } \\
\text { manusia, budaya kerja } \\
\text { organisasi, tata kelola } \\
\text { dan kepemimpinan } \\
\text { serta infrastruktur } \\
\text { rumah sakit sangat } \\
\text { siap akan RME serta } \\
\text { dapat mengatasi } \\
\text { berbagai tantangan } \\
\text { untuk keberhasilan } \\
\text { penerapan RME }\end{array}$ & $\begin{array}{l}\text { Rumah sakit } \\
\text { sangat siap } \\
\text { untuk } \\
\text { implementasi } \\
\text { RME }\end{array}$ \\
\hline $\begin{array}{c}\text { II } \\
50-97\end{array}$ & $\begin{array}{l}\text { Skor ini menunjukkan } \\
\text { bahwa organisasi } \\
\text { memiliki kemampuan } \\
\text { yang baik pada } \\
\text { beberapa komponen } \\
\text { namun masih ada } \\
\text { kelemahan di } \\
\text { beberapa komponen. } \\
\text { Oleh sebab itu } \\
\text { diperlukan identifikasi } \\
\text { dan antisipasi lebih } \\
\text { lanjut pada komponen } \\
\text { yang lemah sehingga } \\
\text { implementasi RME } \\
\text { tetap berjalan dengan } \\
\text { baik }\end{array}$ & $\begin{array}{l}\text { Rumah sakit } \\
\text { cukup siap } \\
\text { untuk } \\
\text { implementasi } \\
\text { RME }\end{array}$ \\
\hline $\begin{array}{c}\text { III } \\
0-49\end{array}$ & $\begin{array}{l}\text { Skor ini menunjukkan } \\
\text { adanya kelemahan di } \\
\text { beberapa komponen } \\
\text { yang penting bagi } \\
\text { keberhasilan } \\
\text { penerapan RME. Oleh } \\
\text { sebab itu diperlukan } \\
\text { identifikasi dan } \\
\text { perencanaan secara } \\
\text { keseluruhan sebelum } \\
\text { melangkah maju } \\
\text { dalam adopsi dan } \\
\text { implementasi RME }\end{array}$ & $\begin{array}{l}\text { Rumah sakit } \\
\text { belum siap } \\
\text { untuk } \\
\text { implementasi } \\
\text { RME }\end{array}$ \\
\hline
\end{tabular}

\section{HASIL DAN PEMBAHASAN}

Penelitian ini menggunakan 82 responden penelitian untuk menilai Kesiapan Rumah Sakit Dharma Kerti Tabanan dalam menerapkan rekam medis elektronik. Responden yang digunakan adalah seluruh tenaga kesehatan dan non kesehatan di Rumah Sakit Dharma Kerti Tabanan. Tiap responden diberikan kuesioner untuk diisi mandiri oleh responden. Berdasarkan kuesioner yang disebarkan kepada 82 responden, terdapat 12 kuesioner yang tidak diisi dan 70 kuesioner yang diisi. Berdasarkan hal tersebut, tingkat pengembalian kuesioner (Respon Rate) penelitian ini adalah sebesar $70 / 82 \times 100 \%=$ $85.4 \%$.

Kuesioner yang tidak diisi oleh responden disebabkan karena responden cukup sibuk dalam bekerja sehingga tidak sempat mengisi kuesioner yang telah diberikan. Tim surveyor yang ditunjuk oleh peneliti juga telah mengingatkan responden dalam mengisi kuesioner yang diberikan namun kuesioner tetap belum diisi sampai batas waktu yang ditetapkan. Adapun gambaran karakteristik sosio-demografis dari 70 responden penelitian ini adalah sebagian berikut.

Tabel 2. Karakteristik Sosio-Demografis Responden Penelitian

\begin{tabular}{|c|c|c|c|}
\hline $\begin{array}{l}\text { No } \\
\text {. }\end{array}$ & $\begin{array}{l}\text { Karakteristik } \\
\text { Sosio-Demografis }\end{array}$ & Frekuensi & $\%$ \\
\hline \multirow[t]{3}{*}{1} & Jenis Kelamin & & \\
\hline & Laki laki & 18 & $25.71 \%$ \\
\hline & Perempuan & 52 & $74.29 \%$ \\
\hline \multirow[t]{4}{*}{2} & Umur & & \\
\hline & $\leq 30$ Tahun & 33 & $47.14 \%$ \\
\hline & 31 - 40 Tahun & 19 & $27.14 \%$ \\
\hline & $>40$ Tahun & 18 & $25.71 \%$ \\
\hline \multirow[t]{4}{*}{3} & Masa Kerja & & \\
\hline & $\leq 10$ tahun & 48 & $68.57 \%$ \\
\hline & 11 - 20 Tahun & 14 & $20 \%$ \\
\hline & $>20$ Tahun & 8 & $11.43 \%$ \\
\hline \multirow[t]{4}{*}{4} & Status & & \\
\hline & Kepegawaian & & \\
\hline & Tenaga Medis & 54 & $77.14 \%$ \\
\hline & Tenaga Non Medis & 16 & $22.86 \%$ \\
\hline \multirow[t]{4}{*}{5} & Jenis Pekerjaan & & \\
\hline & Pegawai Tetap & 48 & $68.57 \%$ \\
\hline & Pegawai Kontrak & 17 & $24.29 \%$ \\
\hline & Lainnya & 5 & $7.14 \%$ \\
\hline
\end{tabular}

Berdasarkan Tabel 2 Diatas, dapat dilihat bahwa sebagian besar responden penelitian adalah perempuan yakni sebanyak $74.29 \%$ dan sebagian besar juga berada pada rentang umur 
31 sampai 40 tahun yakni sebanyak $47.14 \%$. dilihat dari masa kerja, sebagian besar masa kerja responden kurang dari 10 tahun yakni sebanyak $68.57 \%$. dilihat dari status kepegawaian, sebagian besar merupakan tenaga medis rumah sakit yakni $77.14 \%$ dan tenaga tetap rumah sakit yakni $68.57 \%$. Adapun hasil kesiapan rumah sakit tersebut dilihat dari masing masing komponen adalah sebagai berikut.

Tabel 3. Kesiapan Penerapan Rekam Medis Elektronik

\begin{tabular}{|c|c|c|c|}
\hline No & $\begin{array}{l}\text { Kesiapan Penerapan } \\
\text { RME }\end{array}$ & Frekuensi & $\%$ \\
\hline & Kesiapan Budaya & & \\
\hline & Organisasi & & \\
\hline 1 & Kurang Siap & 9 & $12.86 \%$ \\
\hline 2 & Cukup Siap & 48 & $68.57 \%$ \\
\hline \multirow[t]{2}{*}{3} & Sangat Siap & 13 & $18.57 \%$ \\
\hline & Kesiapan Tata Kelola & & \\
\hline 1 & Kurang Siap & 4 & $5.71 \%$ \\
\hline 2 & Cukup Siap & 50 & $71.43 \%$ \\
\hline \multirow[t]{2}{*}{3} & Sangat Siap & 16 & $22.86 \%$ \\
\hline & Kesiapan SDM & & \\
\hline 1 & Kurang Siap & 17 & $24.29 \%$ \\
\hline 2 & Cukup Siap & 40 & $57.14 \%$ \\
\hline \multirow[t]{3}{*}{3} & Sangat Siap & 13 & $18.57 \%$ \\
\hline & Kesiapan & & \\
\hline & Infrastruktur & & \\
\hline 1 & Kurang Siap & 14 & $20 \%$ \\
\hline 2 & Cukup Siap & 41 & $58.57 \%$ \\
\hline 3 & Sangat Siap & 15 & $21.43 \%$ \\
\hline
\end{tabular}

Berdasarkan tabel 3 di atas, terlihat bahwa Rumah Sakit Dharma Kerti Tabanan telah cukup siap dari segi budaya organisasi terkait dengan kesiapan penerapan rekam medis elektronik yakni $68.57 \%$. Dilihat dari komponen kesiapan tata kelola, Rumah Sakit Dharma Kerti Tabanan telah cukup siap dari segi tata kelola terkait dengan kesiapan penerapan rekam medis elektronik yakni $71.43 \%$ dan dilihat dari segi sumber daya manusia (SDM) Rumah Sakit Dharma Kerti Tabanan telah cukup siap dari segi sumber daya manusia (SDM) terkait dengan kesiapan penerapan rekam medis elektronik yakni $57.14 \%$. Selain itu dilihat dari segi infrastruktur, Rumah Sakit Dharma Kerti Tabanan telah cukup siap dari segi tata kelola terkait dengan kesiapan penerapan rekam medis elektronik yakni $58.57 \%$. Kesiapan penerapan rekam medis elektronik juga harus dilihat dari nilai masing masing komponen yang kemudian digambarkan dalam bentuk grafik sehingga dapat terlihat area yang lebih menonjol atau komponen yang lebih siap dan komponen yang kurang siap sehingga bisa memberikan rekomendasi untuk pengembangan penerapan rekam medis elektronik. Adapun nilai masing masing komponen tersebut adalah sebagai berikut.

Tabel 4. Penilaian Kesiapan Rumah Sakit Dharma Kerti Tabanan

\begin{tabular}{llc}
\hline No & Area Kesiapan & $\begin{array}{c}\text { Rata Rata } \\
\text { Skor }\end{array}$ \\
\hline 1 & Kesiapan Budaya Organisasi & 33.1 \\
2 & Kesiapan Tata Kelola & 25.6 \\
3 & Kesiapan SDM & 16.6 \\
4 & Kesiapan Infrastruktur & 11.7 \\
\hline & Total Skor & $\mathbf{8 7}$ \\
\hline
\end{tabular}

Dilihat dari tabel 4 di atas yaitu total skor kesiapan Rumah Sakit Dharma Kerti Tabanan, maka penilaian kesiapan tersebut dapat dikategorikan bahwa Rumah Sakit Dharma Kerti Tabanan cukup siap dalam menerapkan RME. Hal ini diperkuat dengan hasil wawancara kepada informasi yakni secara keseluruhan rumah sakit ini memiliki beberapa hal yang sudah dipenuhi untuk menerapkan rekam medis elektronik tetapi juga masih ada beberapa kekurangan yang perlu dipenuhi.

Dilihat dari kesiapan SDM yakni dari segi pelatihan didapatkan bahwa masih belum ada pelatihan yang terakit langsung dengan rekam medis elektronik. Namun jika dilihat dari segi pengetahuan terhadap rekam medis elektronik, hampir semua responden memahami pentingnya rekam medis elektronik dan juga keuntungan yang diperoleh dari penerapan hal tersebut.

Dilihat dari kesiapan budaya kerja organisasi yakni dari segi budaya terlihat bahwa sebenarnya rumah sakit ini cukup mampu untuk menerapkan rekam medis elektronik karena sudah memiliki sistem informasi rumah sakit yang telah berjalan dengan baik dan juga lingkup rumah sakit ini tidak terlalu kompleks sehingga penerapan rekam medis elektronik bisa lebih cepat. Dari segi keterlibatan pasien didapatkan bahwa 
banyak sekali manfaat atau keuntungan yang diperoleh, salah satunya yang penting adalah kecepatan pelayanan terhadap pasien sehingga pasien tidak terlalu lama menunggu dan juga riwayat pasien dapat lebih mudah dicari sedangkan dilihat dari alur kerja yakni ketersediaan SOP, rumah sakit ini masih belum memliki prosedur kerja atau SOP berkaitan tentang penerapan rekam medis elektronik.

Dilihat dari kesiapan tata kelola dan kepemimpinan, yakni dari segi kepemimpinan yakni pemimpin belum membentuk suatu tim khusus dalam rangka mempercepat penerapan rekam medis elektronik namun komitmen pemimpin untuk menggunakan rekam medis elektronik sudah ada. Dilihat dari segi strategi, rumah sakit telah memiliki perencanaan terhadap penerapan rekam medis elektronik namun belum dirinci dengan detail hal apa saja yang diperlukan untuk mempercepat penerapan rekam medis elektronik. Dilihat dari segi manajemen informasi, rumah sakit telah menyediakan tenaga IT yang cukup paham dengan alur sistem informasi rumah sakit saat ini.

Dilihat dari segi akuntabilitas, rumah sakit memiliki komitmen untuk menerapkan rekam medis yang ditunjukkan dengan adanya pembicaraan terkait dengan vendor atau pihak ketiga untuk penyediaan rekam medis elektronik nantinya. Dilihat dari kesiapan IT yakni dari segi infrastruktur adalah rumah sakit ini memiliki fasilitas IT yang memadai hanya saja belum memiliki IT untuk mendukung penerpan rekam medis elektronik.

Hal ini ditandai dengan hampir semua fungsi pelayanan terhubung pada suatu sistem sehingga mempermudah pelayanan. Dilihat dari segi dukungan manajemen IT, rumah sakit telah memiliki tenaga IT yang handal dan juga memiliki kerja sama dengan vendor untuk mendukung kelancaran sistem informasi rumah sakit. Dilihat dari rencana anggaran atau ekuangan, rumah sakit ini belum menganggarkan khusus untuk percepatan rekam medis elektronik. Anggaran yang disediakan baru sebatas anggaran untuk sistem informasi rumah sakit.

Kesiapan Rumah Sakit Dharma Kerti Tabanan dalam menerapkan RME dapat diketahui dari 4 komponen kesiapan yakni kesiapan dari segi budaya organisasi, kesiapan dari tata kelola dan kepemimpinan, kesiapan dari segi sumber daya manusia dan kesiapan dari segi infrastruktur. Budaya organisasi adalah nilai dan keyakinan yang mendasari identitas organisasi (Kreitner, R and Kinicki, 2010). Pada tingkat organisasi, budaya itu merupakan asumsi dan juga sebuah keyakinan yang dimiliki secara bersama oleh sebuah anggota kelompok untuk membentuk, mempengaruhi perilaku dan memberi petunjuk dalam memecahkan suatu permasalahan (Gibson et al, 2010).

Pada bagian ini budaya organisasi lebih mengarahkan pada perubahan sistem di rumah sakit yang pada awalnya pemakaian rekam medis yang sifatnya masih tradisional yakni secara manual kini berubah ke RME. Pada dasarnya penerapan rekam medis elektronik di rumah sakit bertujuan untuk menciptakan suatu sistem kerja yang efektif dan efisien. Berdasarkan hasil penelitian di beberapa rumah sakit yakni dari tahun 2007 sampai tahun 2009 menunjukkan penerapan rekam medis elektronik memberikan suatu peningkatan kualitas pelayanan dan keselamatan pasien serta efisiensi (Carroll, 2012).

Dilihat dari hasil kesiapan budaya organisasi, Rumah Sakit Dharma Kerti Tabanan berada pada kondisi cukup siap yakni sudah memiliki sistem informasi yang telah berjalan dengan baik dan juga lingkup rumah sakit ini tidak terlalu kompleks namun masih ada beberapa komponen yang kurang yaitu belum adanya gambaran sistem rekam medis elektronik yang akan berjalan dan juga belum adanya SOP terkait hal tersebut. Penelitian ini sejalan dengan penelitian Pratama (2016) yakni kesiapan dari segi budaya organisasi di RSUD Yogyakarta adalah cukup siap dan juga memiliki kekurangan yang sama yakni alur kerja rekam medis elektronik yang belum 
terencana (Pratama, 2016). Pada tahap awal penerapan rekam medis elektronik akan mengakibatkan pergeseran budaya yang awalnya manual kemudian beralih ke elektronik sehingga ini akan memiliki efek fisik dan fisiologis (Shoolin, 2010). Pihak manajemen utamanya pimpinan harus memotivasi penerimaan staf atau pegawai pada penerapan rekam medis elektronik karena hal itu menjadi penentu utama keberhasilan penerapan rekam medis elektronik (Ajami, 2011).

Kepemimpinan dan tata kelola merupakan salah satu komponen yang berpengaruh signifikan terhadap percepatan penerapan rekam medis elektronik. Kepemimpinan pada dasarnya adalah kemampuan seseorang dalam mempengaruhi karyawannya untuk mencapai sebuah tujuan yang telah ditetapkan bersama (Robbins, 2006). Pemimpin memliki peran yang sangat penting terutama dalam hal pengambilan keputusan.

Hal ini menunjukkan bahwa pemimpin memiliki peran sebagai penentu kebijakan yang akan diambil meliputi strategi untuk mengembangkan sebuah inovasi, mengambil sebuah peluang, bernegosiasi dan menjalankan sebuah keputusan secara konsisten. Oleh sebab itu dukungan pemimpin sangat penting dalam kesuskesan penerapan RME.

Dilihat dari hasil komponen kesiapan tata kelola dan kepemimpinan, Rumah Sakit Dharma Kerti Tabanan berada pada kondisi cukup siap yakni pemimpin sudah ada wacana dalam menjalankan RME dan juga sudah memiliki sistem informasi yang terkomputerisasi namun masih ada yang kurang yakni belum terbentuknya tim khusus untuk mempercepat rekam medis elektronik dan juga belum adanya strategi dalam mempercepat penerapan rekam medis elektronik.

Hasil peneltian ini sejalan dengan penelitian Sudirahayu (2016) bahwa pemimpin memiliki komitmen dalam menerapkan RME di sebuah rumah sakit dan juga belum memiliki strategi dalam mempercepat penerapan rekam medis elektronik (Sudirahayu, 2016). Hasil penelitian ini sejalan juga dengan penelitian Pratama (2016) bahwa jajaran manajemen rumah sakit mendukung adanya rekam medis elektronik namun belum masuk dalam perencanaan strategis rumah sakit (Pratama, 2016).

SDM adalah faktor strategis dalam kegiatan yang membuat sumber daya yang lain dapat bekerja dengan baik dan mampu mencapai tujuan secara efektif dan efisien (Simamora, 2006). Hal tersebut menunjukkan bahwa perencanaan terhadap SDM di sebuah organisasi harus terdokumentasi dengan baik dan diusulkan pada bagian personalia di rumah sakit. Kemampuan staf atau pegawai untuk mengoperasikan sebuah komputer jmenjadi salah satu komponen penting yang mendukung pengembangan dan percepatan penerapan RME.

Berdasarkan hasil komponen kesiapan SDM, Rumah Sakit Dharma Kerti Tabanan menunjukkan cukup siap untuk mengembangkan RME yakni sudah memiliki tenaga rekam medis dan tenaga IT masing masing sebanyak 1 orang dan juga sudah memiliki pengetahuan yang cukup tentang rekam medis elektronik. Namun dari segi pelatihan, belum ada pelatihan terkait dengan penerapan rekam medis elektronik.

Penelitian ini sejalan dengan penelitian Pratama (2016) bahwa sudah ada pengetahuan yang cukup tentang rekam medis elektronik yang dimiliki petugas (Pratama, 2016). Namun penelitian ini berbeda dengan penelitian yang dilakukan oleh Sudirahayu (2016) bahwa petugas memiliki pengetahuan yang kurang terhadap rekam medis elektronik (Sudirahayu, 2016). Peningkatan pengetahuan petugas dapat dilakukan melalui suatu pelatihan.

Oleh sebab itu pelatihan terkait dengan rekam medis eletronik menjadi sangat penting. Pelatihan adalah salah satu sarana dalam mengembangkan sebuah potensi yang dimiliki seseorang untuk digunakan dalam hidup dan pekerjaannnya Nur, H., Yaumi, M., Patak, A. A., \& Said, H. (2014). Pelatihan memiliki tujuan untuk meningkatkan dan mengembangkan 
sikap, keahlian dan kemampuan seorang karyawan sehingga kekurangan petugas dapat diketahui dengan baik sehingga dapat dilakukan perbaikan terhadap kekurangan tersebut (Hariandja, 2007).

Kesiapan infrastruktur terkait dengan infrastruktur IT, manajemen IT dan juga keuangan atau anggaran. Pada dasarnya hambatan yang umumnya ditemui dalam pengembangan rekam medis elektronik yaitu berkaitan dengan keuangan atau anggaran untuk menyediakan sebuah infrastruktur teknologi informasi di rumah sakit sehingga menyebabkan terbatasnya infastruktur IT.

Berdasarkan hasil dari area kesiapan Infrastruktur IT, Rumah Sakit Dharma Kerti Tabanan telah cukup siap untuk menerapkan rekam medis elektronik yang ditunjukkan dengan adanya fasilitas yang memadai untuk IT dan adanya dukungan dari pihak vendor namun masih ada yang kurang yaitu anggaran atau keuangan yang spesifik untuk penyelenggaraan rekam medis belum ada.

Kondisi ini sejalan dengan penelitian Pratama (2016) yang mendapatkan bahwa anggaran yang khusus untuk penerapan rekam medis elektronik belum ada (Pratama, 2016). Selain itu penelitian Sudirahayu (2016) mendapatkan bahwa Rumah Sakit Umum Daerah Dr. H.Abdul Moeloek sudah siap untuk menerapkan RME namun disini terkait dengan anggaran untuk pelakasanaan rekam medis elektronik, pihak Rumah Sakit RSUD Dr. H.Abdul Moeloek sudah siap (Sudirahayu et al, 2016). Hasil penelitian ini berbeda dengan penelitian Hidayat (2017) bahwa klinik rawat inap PKU Muhammadiyah Pakem belum memiliki infrastruktur IT yang memadai (Hidayat, Anas Rahmat dan Ersihana Wulan Sari, 2017).

\section{PENUTUP}

Secara keseluruhan, Rumah Sakit Dharma Kerti Tabanan cukup siap untuk menerapkan rekam medis elektronik namun masih terdapat beberapa kekurangan yakni belum adanya gambaran sistem rekam medis elektronik yang akan berjalan, belum adanya SOP terkait hal tersebut, belum terbentuknya tim khusus untuk mempercepat rekam medis elektronik, belum adanya strategi dalam mempercepat penerapan rekam medis elektronik dan belum ada pelatihan terkait dengan penerapan rekam medis elektronik serta belum adanya anggaran atau keuangan yang spesifik untuk penyelenggaraan rekam medis. Oleh sebab itu pihak rumah sakit perlu memperbaiki kekurangan yang dimiliki sehingga dapat mempercepat penerapan RME di rumah sakit.

\section{DAFTAR PUSTAKA}

Ajami, S., Ketabi, S., Isfahani, S., \& Heidari, A. (2011). Readiness Assessment of Electronic Health Records Implementation. Acta Informatica M e d i c a, 19 (4), 224. https://doi.org/10.5455/aim.2011.19.224$\underline{227}$

Andini, \& Rita. (2006). Analisis Pengaruh Kepuasan Gaji, Kepuasan Kerja, Komitmen Organisasi terhadap Turnover d i Rum ah Sakit Roemani Muhammadiyah Semarang (Tesis). Program Magister Manajemen Universitas Diponegoro.

Gibson, J. L., Ivancevich, J. M., \& Donelly, J. H. (2010). Organisasi Jilid 2: Perilaku, Struktur, Proses (N. Adiarni, Ed.). Jakarta: Binarupa Aksara.

Handiwidjojo, W. (2009). Rekam medis elektronik. Universitas Kristen Duta Wacana Yogyakarta, 2(1), 36-41. Re t ri e ve d f r o m https://ti.ukdw.ac.id/ojs/index.php/eksis Larticle/view/383

Hariandja, M. T. E. (2009). Manajemen Sumber Daya Manusia: Pengadaan, Pengembangan, Pengkompensasian, dan Peningkatan Produktivitas Pegawai. Jakarta: PT Grasindo.

Hidayat, A. R., \& Sari, E. W. (2017). Analisis Kesiapan Penerapan Electronic Medical Record di Klinik rawat Inap PKU 
Muhammadiyah Pakem. Indonesian Journal on Medical Science, 4(1), 147-155. Kalogriopoulos, N. A., Baran, J., Nimunkar, A. J., \& Webster, J. G. (2009). Electronic medical record systems for developing countries: Review. Proceedings of the 31st Annual International Conference of the IEEE Engineering in Medicine and Biology Society: Engineering the Future of Biomedicine, EMBC 2009, 1730-1733. https://doi.org/10.1109/IEMBS.2009.5333 $\underline{561}$

Nur, H., Yaumi, M., Patak, A. A., \& Said, H. (2014). Integrating Knowledge Science and Religion. Proceedings of The 1st Academic Symposium on Integrating Knowledge (The 1st ASIK). Retrieved $\begin{array}{llll}f & r & 0 & m\end{array}$ https://books.google.co.id/books?id=vhd YBQAAQBAJ\&pg=PA374\&dq $=p e l \% 5 \mathrm{Cn}$ atihan+adalah\&hl=id\&sa=X\&ei=ZkXtVJ6 0IYuD8QWRz4DQCw\&ved $=0 \mathrm{C} \% 5 \mathrm{CnEY}$ Q6AEwCQ\# $\mathrm{v}=$ onepage\& $\mathrm{q}=$ pelatihan adalah\&f=false

Pettinger, R. (2013). Organizational Behaviour. In Organizational Behaviour. https://doi.org/10.4324/9780203857595

Pratama, M. H. (2016). Analisis strategi pengembangan rekam medis elektronik di Instalasi Rawat Jalan RSUD Kota Yogyakarta (Universitas Muhammadiyah Surakarta). https://doi.org/10.33560/.V5I1.146

Qureshi, Q. A., Ahmad, I., \& Nawaz, A. (2012). Readiness for e-health in the developing countries like Pakistan. Gomal Journal of Medical Sciences, 10(1), 160-163. $\mathrm{R}$ e t ri e v e d f r o m http://gjms.com.pk/ojs/index.php/gjms/a rticle/view $/ 552$

Robbins, S. P. (2006). Perilaku Organisasi (10th ed.). Jakarta: Indeks.

Shoolin, J. S. (2010). Change Management Recommendations for Successful Electronic Medical Records Implementation. Applied Clinical
Informatics, 01(03), 286-292. https://doi.org/10.4338/ACI-2010-01-R$\underline{0001}$

Silow-Carroll, S., Edwards, J. N., \& Rodin, D. (2012). Using electronic health records to improve quality and efficiency: the experiences of leading hospitals. Issue Brief (Commonwealth Fund), 17, 1-40. $\mathrm{R}$ e $\mathrm{t} \mathrm{r}$ i e $\mathrm{ved} \quad \mathrm{f} \mathrm{r} \mathrm{o} \mathrm{m}$ http://www.ncbi.nlm.nih.gov/pubmed/2 2826903

Simamora, H. (2004). Manajemen Sumber Daya Manusia (3rd ed.). STIE YKPN Yogyakarta.

Snyder-Halpern, R. (2001). Indicators of organizational readiness for clinical information technology/systems innovation: a Delphi study. International Journal of Medical Informatics, 63(3), 179-204. https://doi.org/10.1016/S13865056(01)00179-4

Sudirahayu, I., \& Harjoko, A. (2016). Analisis Kesiapan Penerapan Rekam Medis Elektronik Menggunakan DOQ-IT di RSUD Dr. H. Abdul Moeloek Lampung. Journal of Information Systems for Public Health, 1(2), 35-43. Retrieved from https://journal.ugm.ac.id/jisph/article/vi ew/6536

Sudjana, S. (2017). Aspek Hukum Rekam Medis atau Rekam Medis Elektronik sebagai Alat Bukti Dalam Transaksi Teurapetik. Veritas et Justitia, 3(2), 359-383. https://doi.org/10.25123/vej.2685

Tavakoli, N., Jahanbakhsh, M., Mokhtari, H., \& Tadayon, H. R. (2011). Opportunities of electronic health record implementation in Isfahan. Procedia Computer Science, 3 , $\begin{array}{llllllllll}1 & 1 & 9 & 5 & - & 1 & 1 & 9 & 8\end{array}$. https://doi.org/10.1016/j.procs.2010.12.19 $\underline{3}$

Venkatraman, S., Bala, H., Venkatesh, V., \& Bates, J. (2008). Six strategies for electronic medical records systems. Communications of the ACM, 51(11), 140. https://doi.org/10.1145/1400214.1400243 